\title{
Review on the Applications of Apparent Mean Shape Factor on the Integration of Coarse and Fine PSDs Measured by Different Techniques: Quartz Example
}

\author{
U. Ulusoy ${ }^{1, *}$, M. Yekeler ${ }^{1}$, O.Y. Gülsoy ${ }^{2}$, N. A. Aydoğan ${ }^{2}$, C. Biçer ${ }^{1}$ and, Z. Gülsoy ${ }^{1}$ \\ ${ }^{1}$ Department of Mining Engineering, Sivas Cumhuriyet University, TR-58140, Sivas, Turkey \\ ${ }^{2}$ Department of Mining Engineering, Hacettepe University, TR-06532, Ankara, Turkey \\ Email: uulusoy@cumhuriyet.edu.tr
}

\begin{abstract}
In most industry where grinding is utilized, particle size, which is a decisive element in establishing the productivity of production processes and execution of the end product, is analyzed to describe the size distribution of particles in a given sample. In mineral and coal processing, particle size distributions (PSDs) of particulate materials were traditionally accomplished by sieving, which gives inaccurate particle size and PSD below $38 \mu \mathrm{m}$. This paper reviews the studies related to the combinations PSDs of different mill products of the same quartz mineral by using different particle size measurement techniques to build the whole PSDs including coarse and fine PSDs. For this purpose, almost pure quartz mineral (which is the most suitable brittle material that gives first order grinding kinetics) ground by ball and rod mill products that are the most widely used conventional mills in mineral processing were measured by different size analysis techniques, i.e. sieving for coarse sizes, Andreasen pipette sedimentation, and laser diffraction for fine sizes below $38 \mu \mathrm{m}$ and combined them to construct whole size distribution by using apparent mean shape factor, $r$.

The results were satisfactorily well for both cases; PSDs by laser diffraction size distributionsieving and PSDs by Andreasen pipette sedimentation-sieving, i.e., a smooth overlap of corrected laser diffraction and sieving PSDs and Andreasen pipette sedimentation and sieving PSDs were obtained by applying to the particle size distribution with $r$ shifting to the right side of the curves. In the case of determination of PSDs by laser diffraction and sieving, $r$ values determined from the corrected particle size distributions were found to be 1.29 and 1.25 for ball and rod milled products, respectively. The results indicates that there is not significant differences between the shape factors of ball and rod milled products of quartz mineral, i.e. both of them have irregular particles, which deviates from the spherical shape as proved by their SEM microphotographs. On the other hand, for the PSDs by Andreasen pipette sedimentation and sieving, the corrected sedimentation data came closer to the sieving data. It was found that $\mathrm{r}$ values determined from the corrected PSDs of the same quartz mineral ground by ball and rod mill were 1.00 and 1.12 , respectively. The results show that the rod milled products were not more regular in shape than ball milled products as evidenced by SEM pictures and previous works. Thus, this approach can be utilized for the integration of PSDs analyzed by different techniques for coarse and fine sizes of fine particulate coals, minerals, and similar materials ground finely.
\end{abstract}

Keywords: Quartz, sedimentation size, sieve size, laser diffraction size, particle size distribution (PSD), apparent mean shape factor.

\section{Nomenclature}

d $\quad \mathrm{cm}$

D $\quad \mathrm{mm}$

$\mathrm{d}_{50} \quad \mu \mathrm{m}$

$\mathrm{D}_{\mathrm{f}} \mathrm{g} / \mathrm{cm}^{3}$

$\mathrm{D}_{\mathrm{S}} \mathrm{g} / \mathrm{cm}^{3}$

$\mathrm{f}_{\mathrm{C}} \quad--$

g $\quad \mathrm{cm} / \mathrm{sec}^{2}$
Sieving size or particle diameter, the size of the largest particle that can still be existing in the sample inner diameter of mill or particle size measured by any particle size measurement technique

$50 \%$ (by mass) passing size

density of fluid

density of solid particle

fractional powder filling

acceleration due to gravity 


$\begin{array}{lll}\mathrm{H} & \mathrm{cm} & \text { height in sedimentation } \\ \mathrm{J}_{\mathrm{B}} & \% & \text { fractional ball filling } \\ \mathrm{L} & \mathrm{mm} & \text { mill length } \\ \mathrm{N}_{\mathrm{c}} & \mathrm{rpm} & \text { critical speed } \\ \mathrm{PSD} & -- & \text { particle size distribution } \\ \mathrm{r} & -- & \text { apparent mean shape factor } \\ \mathrm{t} & \mathrm{sec} . & \text { settling time } \\ \mathrm{U} & -- & \text { powder-ball loading ratio } \\ \mathrm{v} & \mathrm{cm} / \mathrm{sec} . & \text { velocity } \\ \mathrm{V} & \mathrm{cm}{ }^{3} & \text { mill volume } \\ \mathrm{W}_{0} & \mathrm{~g} & \text { weight of initial sample } \\ \mathrm{W}_{\mathrm{d}} & \mathrm{g} & \text { weight of particle size d } \\ \mu & \mathrm{centipoise}(\mathrm{g} / \mathrm{cm} . \mathrm{sec} .) & \text { viscosity of the fluid }\end{array}$

\section{Introduction}

A particle is a separate part of material irrespective of its size. Particle size, which is a term used to compare dimensions of mostly solid particle, is a critical parameter for a variety of operations in materials science and technology as well as many other branches such as medicine, pharmacology, biology, ecology, energy technology and the geosciences [1].

The behavior and characteristics of particulate material are mainly dependent on their size, morphology and size distributions since the size impacts get progressively crucial, as its size gradually reduced [2]. Precise size measurement is of essential since quality and performance of several particulate products are primarily depend on size distribution of fine particles. So particle size distribution or shortly PSD can be defined as the size and number of observations of particles in a particulate system or group. It influences the attributes of a powder and dispersions in many crucial manner [3] and it is generally presented as percentage of the entire mass of particle hold by a given size fraction. It is significant to determine and check the PSD of particulate materials because particle size is a key index of quality and performance in various industries related to powders such as paint, pigment, cocoa powder used in chocolate, the glass beads used in highway paint, cement and metal particles, pharmaceutical powders, nano-particles, proteins, cosmetics, polymers, soils, abrasives, fertilizers, and etc., [4]. Blending of metal or ceramic powders for producing sintered engineering components can be given as a specific example why controlling and measuring PSD is important [5].

In mineral processing a spectrum of particle sizes (distribution) of ores are produced by size reduction namely crushing and grinding. Particle size is one of the criteria for a product, which has to meet a size specification for industrial minerals. The particle size of the product stream from the mill circuit acts a significant part on the efficiency of the milling operations and consequently the whole plant throughput since it is closely related to the recovery of valuable mineral [6]. In addition, particle size analysis of mill products is important for providing the required liberation of the valuable minerals from the gangue minerals at various particle sizes after grinding and also to enlarge the surface area for accelerating the dissolution [7]. Above all, it is crucial to determine the optimum particle size of the separator feed in the concentration circuits for maximum efficiency by detecting the particle size range at which any separation losses occurred in the plant for the minimization since separation processes mainly depend on the product particle size, which influences the efficiency of the separator [8]. Consequently, exact and honest measurement of particle size and PSD are fundamental for the characterization of ores and minerals. In coal processing technology, particle size and PSD have remarkable effects on wetting [9], flotation recovery [10], flotation kinetics [11] and rheology of coal-water slurries [12]. The proper PSD of the coal is required for an efficient combustion of pulverized carbon as PSD determines the performance of the fluidized bed coal combustor [13]. In the mining industry of coal and ores as well as several other fields using size analysis, the sieve size distribution is the common definition of particle size because laboratory sieving gives good results with great accuracy for all particle sizes larger than $38 \mu \mathrm{m}$ when good procedures and the correct equipment is used for the measurement. Below $38 \mu \mathrm{m}$, the surface energy of particles gets substantial, and the measurements are affected by agglomeration of particles because of van der Waals forces. This makes particles retained on the sieve even when they are smaller 
than the sieve opening. Therefore, slight errors frequently become obvious below $38 \mu \mathrm{m}$ along with the cumulative PSD displaying a small alteration of slope because of the extra particles accumulated below the sieves smaller than $38 \mu \mathrm{m}[14]$.

But, PSD analysis must be exact and reliable, since important alterations or modifications in processing plant operations can be made according to the laboratory test results. Therefore controlling PSD is important for maximum efficiency and quality of the products [15, 16]. PSD analysis have commonly utilized with accuracy for spherical particles. However, in practice particles are mostly irregular and size characterization should also contain knowledge about shape of irregular particles. In addition, their characterization in the course of analysis is strongly related to the method of measurement utilized, therefore PSD determination is more significant labor due to the variability of the shape and density of particles $[17,18]$ for understanding their physical and chemical attributes. Different techniques of particle size measurement give different results of PSDs but conversion from one to another is possible only when the shape factor is constant since usually the shape is a function of particle size [19].

Production of micronized quartz particles is mainly required for mineral fillers in various industries such as glass, paint, abrasives, refractory, and precision instruments. The suitability of fine quartz particles for different industrial applications is determined by PSD. For example PSD is one of the important properties of minerals used in paint [20]. Therefore, this paper reviews the studies [21, 22] related to the combinations PSDs of different mill products of the same quartz mineral by using different particle size measurement techniques to build the whole PSDs including coarse and fine PSDs. For this purpose almost pure quartz mineral since this material had been used in many previous tests, proved to be very consistent in grinding and sieving and also exhibits more brittle behavior for first order breakage kinetics were used to grind in ball and rod mill, which are the most widely used conventional mills. Then, fine and coarse PSDs of ball and rod mill products were measured by different size analysis techniques (namely, sieving, Andreasen pipette sedimentation and laser diffraction) and combined to construct whole PSDs by using apparent mean shape factor, $r$, which is also important for the bringing out of the shape information to be extracted from the difference of the two PSDs.

\section{Theoretical Background}

\subsection{Techniques of Particle Size Measurement}

Sieving, which is one of the oldest methods [23, 24] of PSD analysis, is commonly used in mineral processing because it is simple, cheap and regarded as a standard practice. It includes shaking the sample by a sieve series stacked from the biggest to the smallest [3]. Then, calculation of the weight percentage of each size fraction can be made by weighing the samples retained on each sieve when passing a known amount of sample material in proper sequence through smaller sieves [8]. It gives a mass distribution and PSD report as cumulative distribution. Sieving measures a size termed as the sieve diameter, which is relied on the upper limit of the width and thickness terms of the particle since the length of the particle does not impede its transition through the sieve opening except for highly rodlike particles. Therefore, classification in sieving accomplished based on particle width. If it is performed meticulously using standard procedure, it produces reliable and reproducible results about PSD [25] for particles coarser than $38 \mu \mathrm{m}$, but measurement for dry powders under $38 \mu \mathrm{m}$ is not easy. Although wet sieving is thought to overcome this problem the results generally yield very poor reproducibility [26]. Therefore, substantial information is also included in the PSD of ultrafine minerals below $38 \mu \mathrm{m}$ [27].

Sedimentation technique, which is versatile, because it can deal with any powder that can be dispersed in a liquid, has also been used as a traditional method for the paint and ceramics industry in the applicable range of $2-50 \mu \mathrm{m}[28,26]$. Andreasen pipette, is a laboratory tool for sedimentation technique to determine the velocity of particles settling in a fluid because of the gravitational forces acting on the particle, versus the buoyancy of the fluid and other drag forces [3]. It allows a homogeneous suspension to settle in a glass cylinder and gives size known as Stokes diameter, which is simply a comparison of the particle's settling rate to a sphere settling at the same rate. Even though it is cheap, analysis is tedious and time-consuming [24]. PSD can be measured by the falling velocity of particles suspended in a viscous liquid, i.e., each representative sample, which will have deposited under 
the sampling level is taken from the settling suspension at a constant horizontal level for a period of time.

Laser diffraction, which is known for its operational simplicity gives robust and versatile solutions for PSD analysis since today's laboratory instruments are more flexible, easy to use and, more automated [29] therefore, this technique is now become a popular and standard in the laboratory [30] for particle sizes between 0.1 and $2000 \mu \mathrm{m}$ [31]. It is based on the assumption of diffraction angle, which is inversely proportional to particle size, i.e. the observed angle of light scattering increments logarithmically as particle size lessens. Besides, scattering intensity is also contingent on particle size, decreasing with the volume of particle. Hence, big particles scatter light at lower angles with great intensity, on the other hand small particles scatter at greater angles, but with small intensity [31]. The data of angular scattering intensity is then analyzed to figure out the size of the particles responsible for the formation of the scattering pattern based on the Mie theory [30] and described by the volume equivalent sphere diameter as volume distribution, which is also the same as the weight distribution for constant density.

\subsection{Approach of Apparent Mean Shape Factor (r)}

As stated above sieving is the most commonly accepted and applied PSD analysis method in the mining and mineral industry and therefore a single PSD integrated coarse and fine size distribution extended to sub-sieve sizes (below $38 \mu \mathrm{m}$ ) is frequently in demand. For this aim, the particle size measured by the particle size measurement technique is multiplied by a well known factor named as the apparent mean shape factor $\mathrm{r}$, which is defined previously by Allen [2]: the instrument size must be multiplied to give the sieving size at which the same mass percentage less than size is obtained as stated by the equation 1 .

$$
r=\frac{\mathrm{d}}{D}
$$

where D represents the particle size measured by any particle size measurement technique and $d$ is denoted by the particle size measured by sieving. It should be noted that, $r$ is not the same for all material but depends on the PSD being analyzed. That's why it is called as an apparent mean shape factor. In this review, $\mathrm{r}$ factor was utilized as the ratio of the $50 \%$ (by mass) passing size (which is also known as $\mathrm{d}_{50}$ ) to the geometric mean sieving size as defined by the equation 2 [32], which yields a method of calculating the factor according to the calibration of an instrument by a $2^{1 / 2}$ sieve size fraction and helps to unite PSDs, which have the Schuhmann form of cumulative PSD [33]:

$$
r=\frac{\mathrm{d}_{50}}{(53 \times 38)^{1 / 2}}
$$

In other words, $r$ corresponds to the Schuhmann plots shifted the PSD curve by any particle size measurement technique to the right (or sometimes left) by the multiplication of the $\mathrm{r}$ factor to get the corresponding sieving PSD, i.e., $r$ factor actually describes the shape differences between $2^{1 / 2}$ sieve size fractions of milled materials.

Because, it is very difficult to obtain PSDs of fine industrial particles by using sieving technique, which is not so true for less than $38 \mu \mathrm{m}$, the PSDs of fine particles by using different techniques, such as sieving, Andreasen pipette sedimentation and laser diffraction can be easy and the entire PSD including coarse and fine PSD can be integrated by the combination of the two PSDs of the material by different sizing techniques, i.e., fine PSD of sedimentation or laser diffraction and coarse PSD of sieving. This approach also reveals the shape information (apparent mean shape factor) from the difference of the two PSDs for the same material by utilization of different sizing techniques.

\section{Experimental}

\subsection{Materials}

In this review almost pure quartz mineral, which includes $97.20 \% \mathrm{SiO}_{2}$ as illustrated by Table 1 , ground by ball and rod mill (which are the most widely used conventional mills in mineral processing) products were used $[21,22]$ to combine PSDs of them as illustrated in XRD pattern and SEM output by Figure 1. 
The specific gravity of quartz mineral used in this work was determined by the pycnometer test as 2.65 $\mathrm{g} / \mathrm{cm}^{3}$.

Table 1. The chemical compositions of quartz minerals used in this study (modified from [21, 22].

\begin{tabular}{cc}
\hline Compound & $\%$ \\
\hline $\mathrm{SiO}_{2}$ & 97.20 \\
$\mathrm{Fe}_{2} \mathrm{O}_{3}$ & 0.07 \\
$\mathrm{Al}_{2} \mathrm{O}_{3}$ & 1.41 \\
$\mathrm{~K}_{2} \mathrm{O}$ & 0.27 \\
$\mathrm{TiO}_{2}$ & 0.06 \\
$\mathrm{CaO}$ & 0.20 \\
$\mathrm{MgO}$ & 0.08 \\
$\mathrm{Na}_{2} \mathrm{O}$ & 0.16 \\
\hline
\end{tabular}

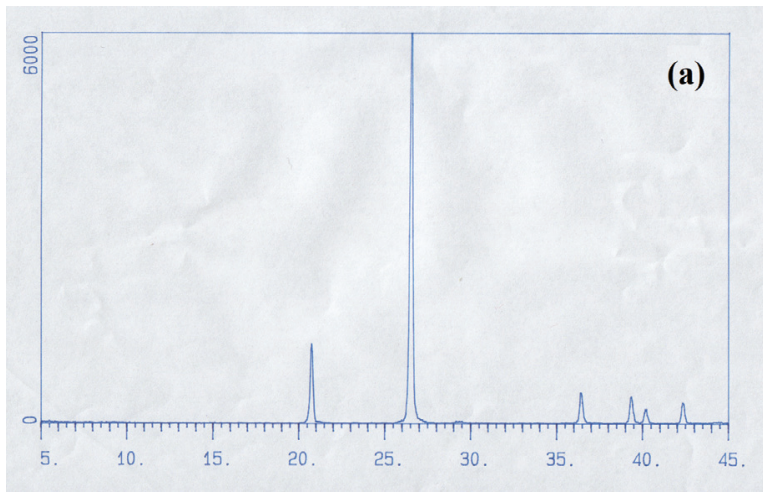

(a)

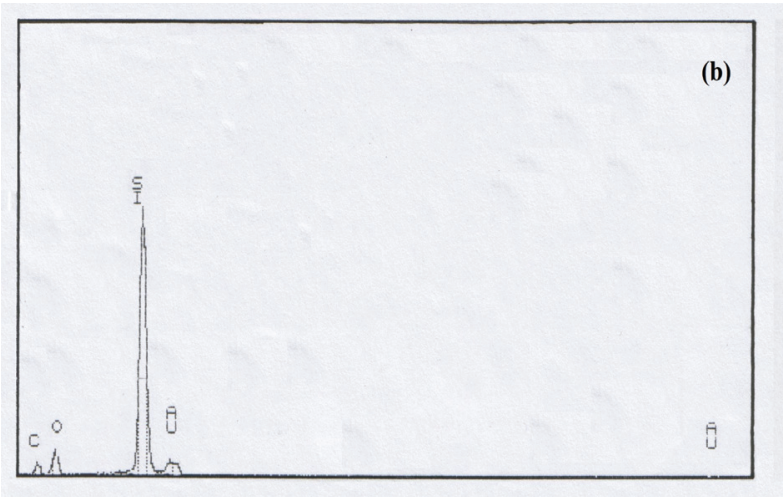

(b)

Figure 1. Mineralogical analysis of the industrial minerals determined by techniques of (a) XRD (modified from $[22])$ and (b) SEM

\subsection{Grinding Tests}

The grinding tests were used as the same method of previously reported studies [34, 35] as summarized in Table 2. Two conventional mills, namely laboratory ball $(200 \mathrm{x} 184 \mathrm{~mm})$ and rod mills $(200 \mathrm{x} 280 \mathrm{~mm})$ were performed in dry conditions using with $5475 \mathrm{~kg}$ of stainless steel balls of 30 and $26 \mathrm{~mm}$ and 22600 $\mathrm{kg}$ of stainless steel rods of 29, 24 and $19 \mathrm{~mm}$ in size, respectively. 16 minutes of grinding time was used in this work for both milling. While for ball milling, feed size fraction was $-800+600 \mu \mathrm{m}$ with a weight of $367.3 \mathrm{~g}$ along with a ball filling of $20 \%$ of the mill volume filled by the ball bed, $-4.75+3.35 \mathrm{~mm}$ of feed size fraction was used with a weight of $745.5 \mathrm{~g}$ for rod milling.

\subsection{PSD Analysis by Different Size Analysis Techniques (Sieving, Laser Diffraction and Andreasen Pipette Sedimentation)}

After grinding the same quartz samples for 16 minutes, a representative sample by cone and quartering technique was first wet sieved and then dry sieved for 10 minutes in a Ro-tap shaker without excessive abrasion from a sieving kinetics study using Retsch Test sieve series comprise $4750 \mathrm{~mm}, 3350 \mathrm{~mm}, 800$, $600,425,250,150,106,75,53$ and $38 \mu \mathrm{m}$ for rod milling, while 800, 600, 425, 250, 150, 106, 75, 53 and $38 \mu \mathrm{m}$ sieves were used for ball milling. Grab sampling method was used for the samples of $-38 \mu \mathrm{m}$ and $53+38 \mu \mathrm{m}$ powder for the Andreasen pipette sedimentation and laser diffraction particle size analysis tests.

The sedimentation tests were accomplished by using an Andreasen pipette (Figure 2), which includes of a $200 \mathrm{~mm}$ graduated cylindrical flask containing an initially homogenous suspension and a pipette 
linked to a $10 \mathrm{ml}$ reservoir via a two-way stopcock [21].

Table 2. Grinding conditions of the minerals studied (modified from [21]).

\begin{tabular}{|c|c|c|c|}
\hline Type of milling & Elements & Parameters & Values \\
\hline \multirow[t]{15}{*}{ Ball Milling } & \multirow{3}{*}{ Mill } & Length $\mathrm{x}$ Inner diameter $(L \times D), \mathrm{mm}$ & $184 \times 200$ \\
\hline & & Critical speed $N_{c}, \mathrm{rpm}$ & 102 \\
\hline & & Operational speed ( $75 \%$ of critical speed), rpm & 76 \\
\hline & \multirow{6}{*}{ Balls } & Type & Stainless steel \\
\hline & & Diameter, mm & 26,30 \\
\hline & & Average ball weights, $\mathrm{g}$ & $68.19,118.18$ \\
\hline & & Specific gravity, $\mathrm{g} / \mathrm{cm}^{3}$ & 7.90 \\
\hline & & Fractional ball filling, $J_{B}$ & 0.2 \\
\hline & & Total ball weights, $\mathrm{kg}$ & 5475 \\
\hline & \multirow{6}{*}{$\begin{array}{l}\text { Quartz } \\
\text { sample }\end{array}$} & Specific gravity, $\mathrm{g} / \mathrm{cm}^{3}$ & 2.65 \\
\hline & & Total powder weight, $\mathrm{g}$ & 367.3 \\
\hline & & Grinding time, min. & 16 \\
\hline & & Fractional powder filling, $f_{c}$ & 0.04 \\
\hline & & Powder-ball loading ratio, $U$ & 0.5 \\
\hline & & Feed size, $\mu \mathrm{m}$ & $-800+600$ \\
\hline \multirow[t]{3}{*}{ Rod Milling } & \multirow{3}{*}{ Mill } & Length $\mathrm{x}$ Inner diameter $(L \times D), \mathrm{mm}$ & $280 \times 200$ \\
\hline & & Critical speed $N_{c}, \mathrm{rpm}$ & 102 \\
\hline & & Operational speed ( $50 \%$ of critical speed), rpm & 51 \\
\hline \multirow{9}{*}{ a } & \multirow{5}{*}{ Rod } & Type & Stainless steel \\
\hline & & Diameter, mm & $19,24,29$ \\
\hline & & Average rod weights, $g$ & $669,1041,1521$ \\
\hline & & Specific gravity, $\mathrm{g} / \mathrm{cm}^{3}$ & 7.90 \\
\hline & & Total rod weights, $\mathrm{kg}$ & 22600 \\
\hline & \multirow{4}{*}{$\begin{array}{l}\text { Quartz } \\
\text { sample }\end{array}$} & Specific gravity, $\mathrm{g} / \mathrm{cm}^{3}$ & 2.65 \\
\hline & & Total powder weight, $g$ & 745.5 \\
\hline & & Grinding time, min. & 16 \\
\hline & & Feed size, $\mu \mathrm{m}$ & $-4750+3350$ \\
\hline
\end{tabular}

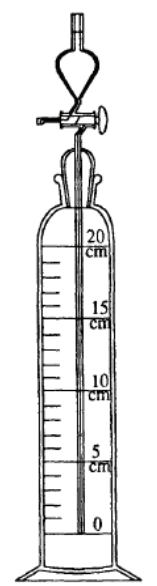

Figure 2. Andreasen pipette apparatus used in this experimental works for the sedimentation tests [21].

Since there is a certain particle size, $d$, which represents the size of the largest particle that can still be existing in the sample equating to each settling length, $\mathrm{H}$ and time, $\mathrm{t}$, Stokes diameter distribution of the powder are calculated from Stokes' law for the various sampling times [8] as given in equation 3. 
The sedimentation procedure is followed by taking fixed volume of the sample at certain height, $\mathrm{H}$ under the suspension surface after a sedimentation time, t. [36].

$$
v=\frac{d^{2} g\left(D_{s}-D_{f}\right)}{18 \mu}
$$

where $\mathrm{v}$ is velocity, $\mathrm{cm} / \mathrm{sec}$; $\mathrm{d}$ is particle diameter, $\mathrm{cm} ; \mathrm{g}$ is the gravity acceleration, $\mathrm{cm} / \mathrm{sec}^{2} ; \mathrm{D}_{\mathrm{S}}$ is density of solid particle, $\mathrm{g} / \mathrm{cm}^{3} ; \mathrm{D}_{\mathrm{f}}$ is density of fluid, $\mathrm{g} / \mathrm{cm}^{3}$ and $\mu$ is viscosity, centipoises $(\mathrm{g} / \mathrm{cm} . \mathrm{sec})$.

The solid concentration of the suspension in the pipette is about $1 \%$ by weight with distilled water having a viscosity of $0.0113 \mathrm{cp}(\mathrm{g} / \mathrm{cm} . \mathrm{sec})$ at room temperature $\left(20^{\circ} \mathrm{C}\right)$. Once the pipette was agitated 3 times by turning it upside down to make the suspension homogenous, an initial sample $\left(\mathrm{W}_{0}\right)$ was taken by applying suction to the top of the reservoir (10 ml volume) instantly by adjusting the two-way stopcock at zero time $(\mathrm{t}=0)$ when the pipette was put into a smooth place, afterwards the stopcock was inverted and letting the sample to pour into the glass container. The current suspension level was recorded after each sample was drawn. Then, next samples were drawn based on the calculated settling times, t (Table 3) of particles having 30, 25, 20, 15, 10 and $5 \mu \mathrm{m}$ size using the equation 4 . The time required for particles to settle in the Andreasen pipette of height $\mathrm{H}$ can be expressed as:

$$
t=\frac{18 H \mu}{d^{2} g\left(D_{s}-D_{f}\right)}
$$

Table 3. Settling times calculated from the Stokes' equation for the $-38 \mu \mathrm{m}$ fractions (modified from [21])

\begin{tabular}{cc}
\hline Particle size $(\mu \mathrm{m})$ & Settling time $(\mathrm{min})$. \\
\hline 30 & 4 min. $25 \mathrm{sec}$. \\
25 & 6 min. $15 \mathrm{sec}$. \\
20 & 9 min. $33 \mathrm{sec}$. \\
15 & 16 min. $40 \mathrm{sec}$. \\
10 & 36 min. 35 sec. \\
5 & 146 min. 40 sec. \\
\hline
\end{tabular}

PSD determination of $2^{1 / 2}$ sieve size fractions $(-53+38 \mu \mathrm{m})$ by Andreasen pipette was accomplished by using the same routine of sedimentation test, which was repeated for particles having sizes of 53, 45, 38, $30 \mu \mathrm{m}$ according to the new settling times calculated by the equation 2. Settling times calculated from the Stokes' equation for the $-53+38 \mu \mathrm{m}$ fractions were given in Table 4 .

Table 4. Settling times calculated from the Stokes' equation for the $-53+38 \mu \mathrm{m}$ fractions of (modified from [21]).

\begin{tabular}{cc}
\hline Particle size $(\mu \mathrm{m})$ & Settling time $(\mathrm{min})$. \\
\hline 53 & $1 \mathrm{~min} .25 \mathrm{sec}$. \\
45 & $1 \mathrm{~min} .56 \mathrm{sec}$. \\
38 & $2 \mathrm{~min} .39 \mathrm{sec}$. \\
30 & $4 \mathrm{~min} .10 \mathrm{sec}$. \\
\hline
\end{tabular}

At the end of the sedimentation test, all samples collected were dried in the oven at $75{ }^{\circ} \mathrm{C}$ and afterwards determined their weights using a balance (readability of $0.0001 \mathrm{~g}$ ) to form the cumulative PSD, which gives the fraction of the original material having a particle size less than $d$, using the ratio of weight of sample taken to the corresponding initial weight [8] as in the equation 5.

$$
\text { Cumulative weight } \% \text { passing }=\frac{\mathrm{W}_{\mathrm{d}}}{\mathrm{W}_{0}} \times 100
$$

where $W_{d}$ is weight of particle size $d, W_{0}$ is weight of initial sample.

In the case of PSD analysis by laser diffraction the instrument of Sympatec Helos, (H1305 model) [37], was used. It is an optical instrument based on the measurement of laser light scattered by the particles in the forward direction using Mie Theory. 


\section{Results and Discussion}

\subsection{Integration of PSDs by Andreasen Pipette Sedimentation and Sieving Techniques}

PSDs of quartz sample ground in ball and rod mills determined by sieving were given in Figure 3 (a). By multiplying the value of cumulative weight \% finer than $38 \mu \mathrm{m}$ with PSDs measured by Andreasen pipette sedimentation technique PSDs of quartz sample ground by ball and rod mills determined by sedimentation method were plotted as in Fig. 3 (b). Although the PSDs are nearly the same in Figure 3 (a) the differences in the PSD curves were appeared in fine sections of the differently milled quartz sample as seen from Figure 3 (b). This tells us some shape differences when the same mineral ground by different mills.

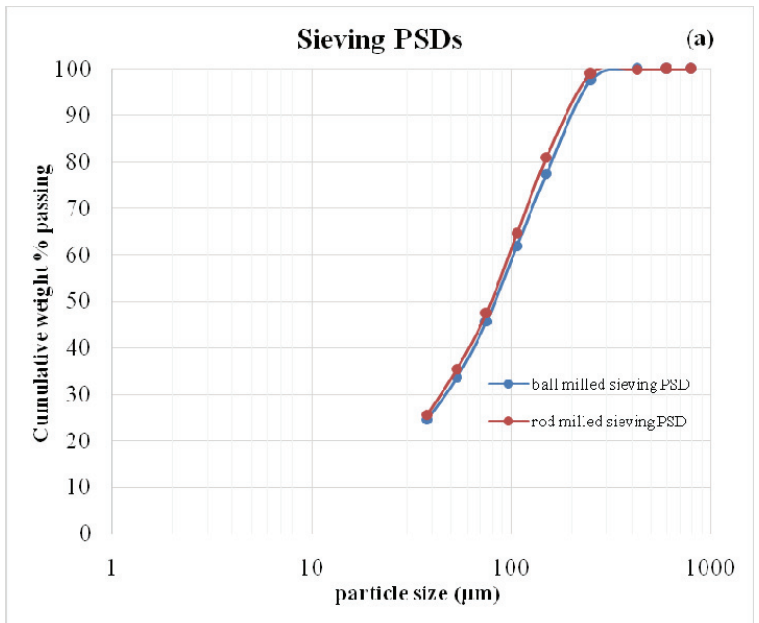

(a)

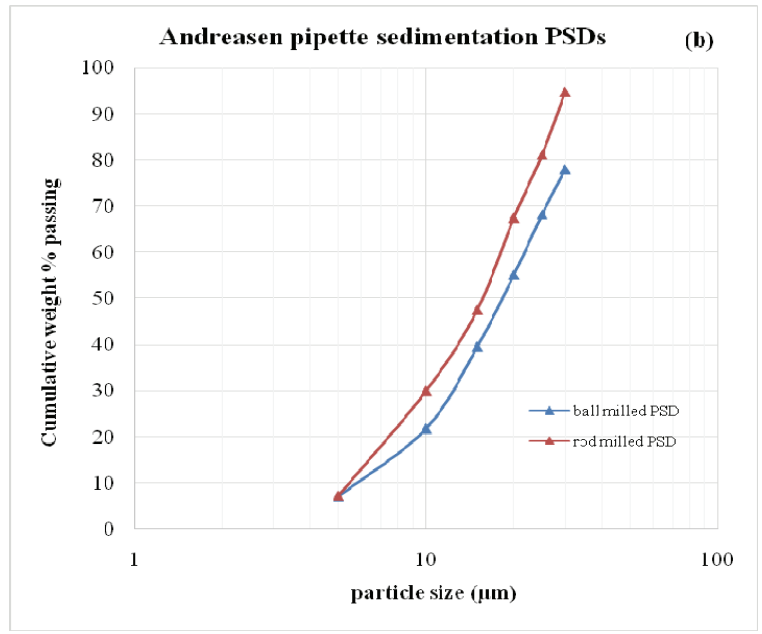

(b)

Figure 3. PSDs of quartz minerals ground in ball and rod mill by (a) Sieving and (b) Andreasen pipette sedimentation techniques (Redrawn from [21])

Combining the coarse and fine PSD by sieving and sedimentation Figure 4 (a), which shows the uncorrected PSDs of quartz mineral ground by different mills determined by the combination of two different techniques was formed. Looking at the curves of whole PSD formed by this approach fine section of the curves for rod milling product does not fit into the coarse section which was measured by sieving, therefore this disagreement between coarse and fine PSDs measured by different techniques for rod mill product can be used as a source of additional information on particle shape [38] but a good trend was obtained by ball milling product indicating that there is no need to application of $\mathrm{r}$ factor, i.e, the particle size measured by the sedimentation technique was well extended by the geometric mean sieve size for the ball mill product. Thus, while the sedimentation size distribution should be shifted right for the rod milled quartz product to obtain equivalent sieve size distribution, there is no need to multiply the $\mathrm{r}$ factor for the ball milled quartz therefore the $\mathrm{r}$ value was assumed to be unity $(\mathrm{r}=1.00)$.

Then the $\mathrm{d}_{50}$ values were calculated as given in Table 5 from the sedimentation tests for the $2^{1 / 2}$ sieve size fraction $(-53+38 \mu \mathrm{m})$ of rod milled quartz sample, apparent mean shape factor, $r$, was ascertained based on the equation 2. Afterwards, new particle sizes were determined by multiplying the particle size by $\mathrm{r}$ factor, so that shifting to the right rod milled quartz, finally, corrected PSD curves were obtained as depicted by Figure 4 (b), which confirms that there is good agreement between the sieve and sedimentation PSD and these corrected PSD curves release true information about the sizes below 38 um size. 


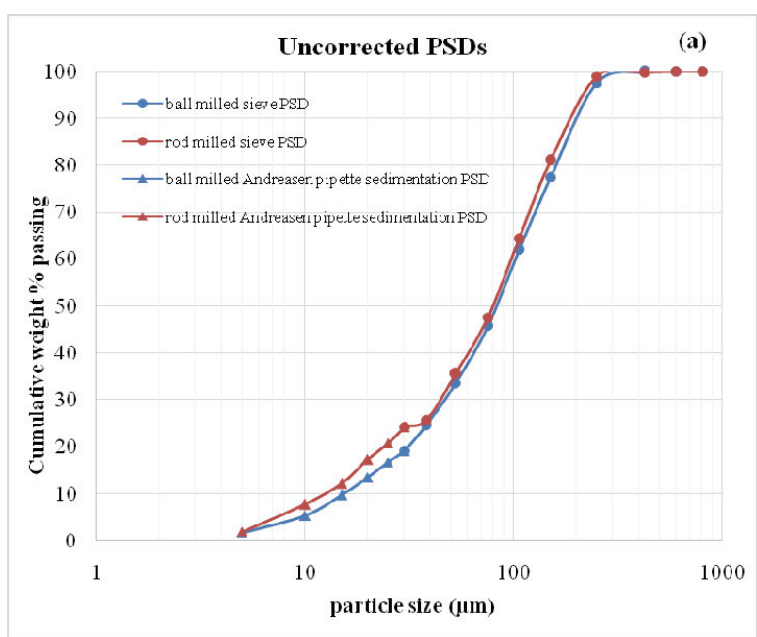

(a)

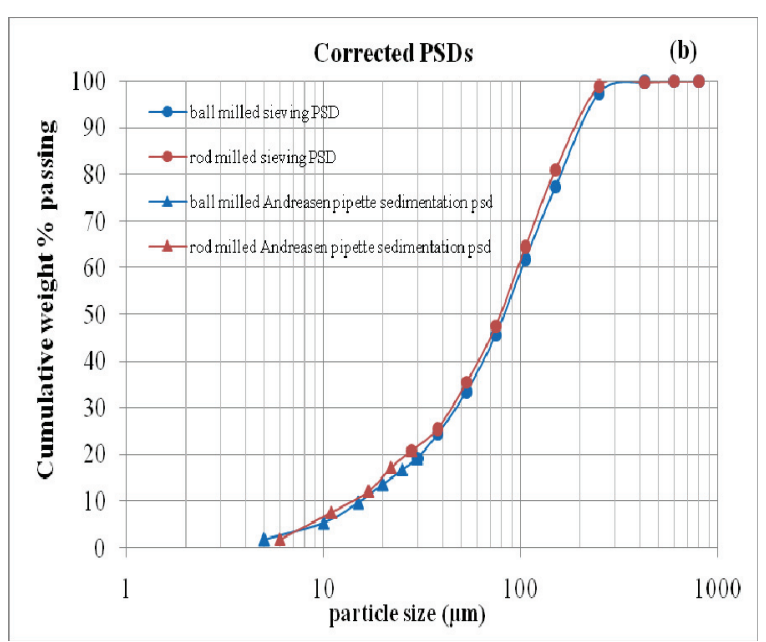

(b)

Figure 4. (a) Uncorrected and (b) Corrected PSDs of ball and rod milled quartz by combination of PSDs measured by sieving and Andreasen pipette sedimentation techniques (Redrawn from [21])

Table 5. values of $d_{50}$ and apparent mean shape factor $(r)$ determined by $2^{1 / 2}$ order size fraction $(-53+38 \mu \mathrm{m})$ for quartz minerals measured by Sympatec laser diffraction and Andreasen pipette sedimentation techniques, respectively [21, 22].

\begin{tabular}{llcc}
\hline Method & Mill product & $\mathrm{d}_{50}(\mu \mathrm{m})$ & Apparen apparent mean shape factor $(r)$ or $(1 / r)$ \\
\hline laser diffraction & Ball & 34.7 & $1.29(r)$ \\
& Rod & 36.0 & $1.25(r)$ \\
\multirow{3}{*}{ sedimentation } & Ball & 35 & $1.00^{*}(1 / r)$ \\
& Rod & 40 & $1.12(1 / r)$ \\
\hline
\end{tabular}

* assumed to be unity since no corrections needed in the PSD see (Figure 4 (a))

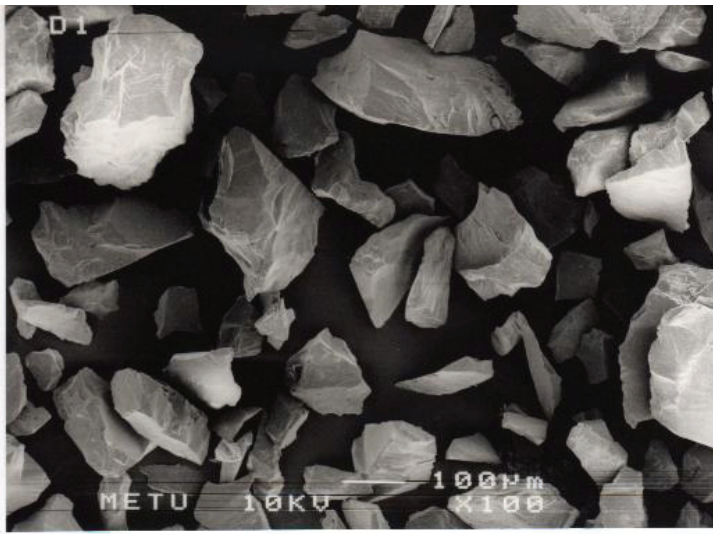

(a)

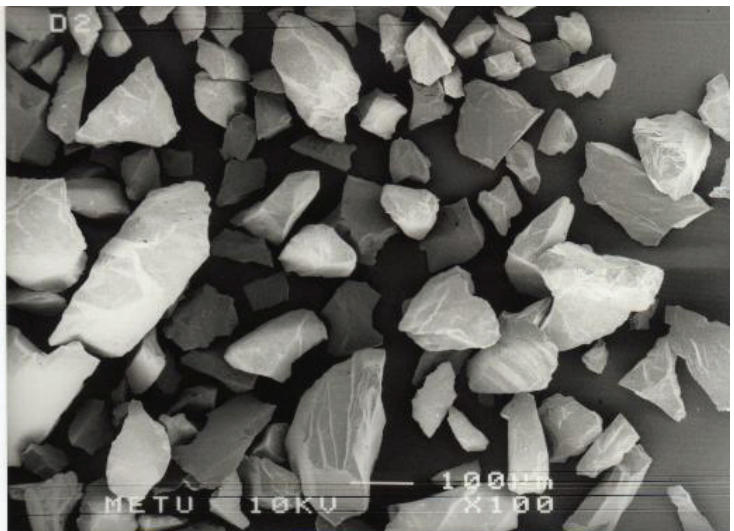

(b)

Figure 5. SEM microphotographs for (a) ball and (b) rod mill products of quartz (x100) (from [21, 22])

The SEM microphotographs about the different milled quartz products in Figure 5 gives also some evidence related to the shape differences between the sedimentation and sieving data and $\mathrm{r}$ factors. in fact, this work gives conclusion of rounder particles have produced by balled milling comparing to rod milling products as good agreement with the previous studies [39, 35, 40], i.e., r value of 1.00 for ball milled quartz was explained by the differences between the material structure of the minerals used, i.e., the material properties have as much marked effects as the mill type reported by $[41,42,39,35]$. It 
should also be noted that, the Stokes equation theoretically prevails for only spherical particles. But, the difference between the sedimentation and sieving PSD does not represent erroneousness on the contrary releases a useful information for particle shape. The more irregular the particle, the smaller is the shape factors. As shown by Figure 5 from the SEM microphotographs, the rod milled product of quartz studied does not have more regular shape according to the particle shape of ball milled products of the same mineral. This was attributed to the different breakage mechanism acted in the ball and rod milling.

\subsection{Integration of PSDs by Laser Diffraction and Sieving Techniques}

While Figure 6 (a) illustrates the coarse PSDs of by ball and rod mill products by using sieving technique in Schuhmann form down to $38 \mu \mathrm{m}$ size, fine PSDs below $38 \mu \mathrm{m}$ by laser diffraction method for the same samples ground in different mills were represented by Figure 6 (b) indicating also a good smooth size distribution. Both of them in deed, show small differences between the ball and rod milled particles.

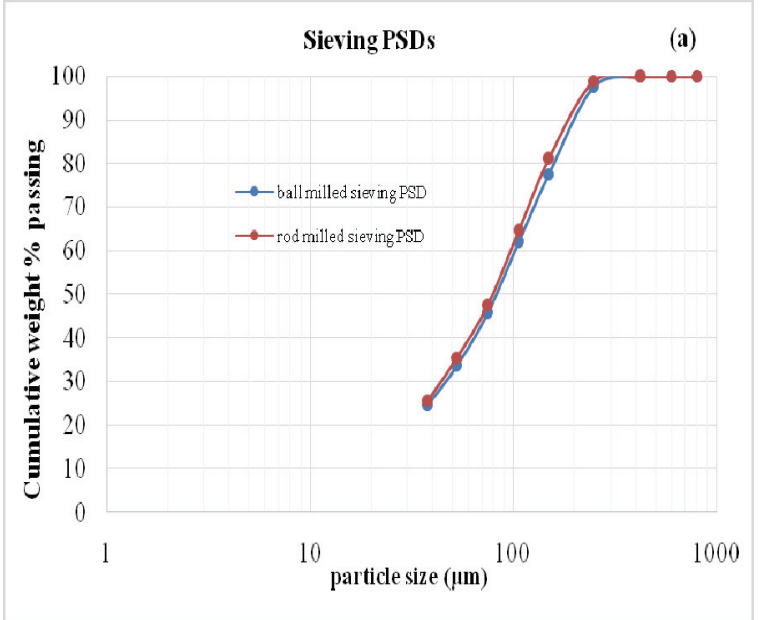

(a)

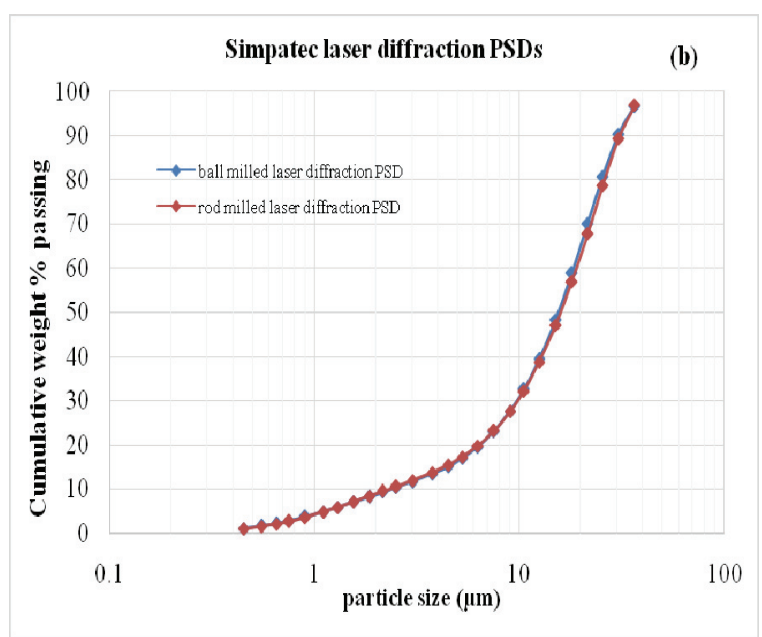

(b)

Figure 6. PSDs of quartz minerals ground in ball and rod mill by (a) Sieving and (b) laser diffraction techniques (Redrawn from [22])

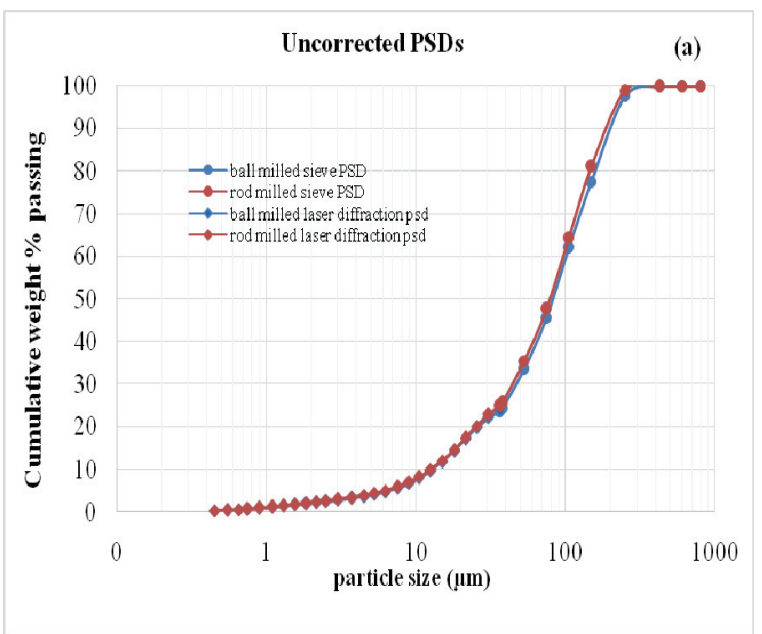

(a)

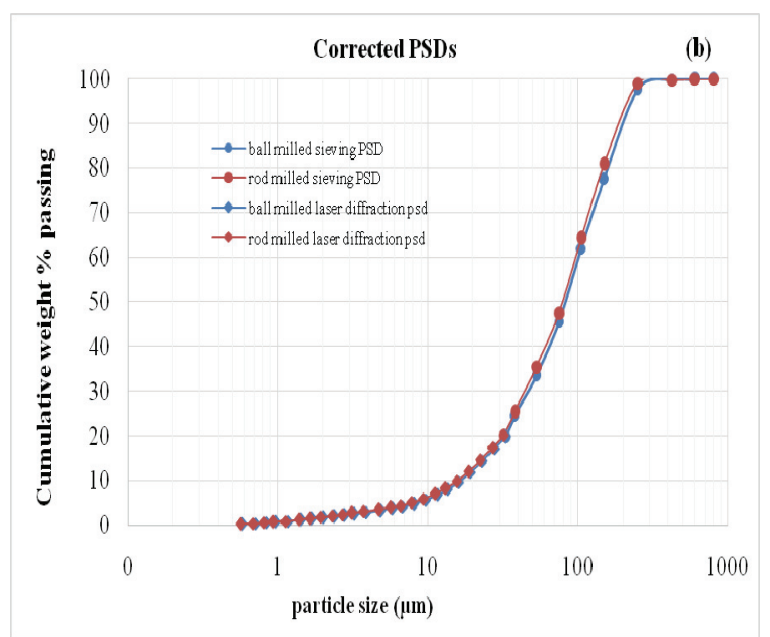

(b)

Figure 7. (a) Uncorrected and (b) Corrected PSDs of ball and rod milled quartz by combination of PSDs measured by sieving and laser diffraction techniques (Redrawn from [22]) 
For the integration of coarse and fine PSDs measured by different techniques, namely sieving and laser diffraction techniques, the uncorrected PSDs on a log-linear scale of the same quartz samples ground by different mills were produced by multiplying the cumulative undersize value of $38 \mu \mathrm{m}$ for sieving technique by the values of cumulative weight $\%$ undersize for laser diffraction technique as depicted by Figure 7 (a). Even though PSD data were well presented Figure 7 (a) there were some deviations between the fine and coarse PSDs by laser diffraction size distributions and sieve size distributions. This could be useful information on particle shape of the same material by different techniques $[43,44,36,2,32,33,38]$.

The sieved fraction size of (geometric mean size fraction) $-53+38 \mu \mathrm{m}$ for quartz mineral ground by ball and rod mills was measured by laser diffraction sizing technique. Then, apparent mean shape factors, $r$, were calculated based on the equation 2 once $\mathrm{d}_{50}$ values were found from the laser diffraction tests for the $2^{1 / 2}$ sieve size fraction $(-53+38 \mu \mathrm{m})$ as given in Table 5. Afterwards, the corrected PSDs (Figure 7 (b) were obtained by utilization of apparent mean shape factor (multiplying of the particle size with $\mathrm{r}$ factor), thereby shifting the sieving PSDs to the right for the rod milled barite and quartz and ball milled quartz. Table 5 also shows the calculated apparent mean shape factors from the corrected particle size distributions of quartz minerals ground by ball and rod mills. $\mathrm{r}$ values were found as 1.29 and 1.25 for ball and rod mill products, respectively, i.e., both of them are nearly the same and indicating that more deviation from the shape of sphere.

\section{Conclusion}

As it is too difficult to obtain a PSD of fine industrial particles by using sieving technique, which is not so true for less than $38 \mu \mathrm{m}$, the PSDs of fine particles by using another different techniques, such as Andreasen pipette sedimentation and laser diffraction can be easy and the entire PSD including coarse and fine PSD can be integrated by the combination of the two PSDs of the same material by these different sizing techniques, i.e., fine PSD of sedimentation or laser diffraction and coarse PSD of sieving by utilizing an approach of apparent mean shape factor, which also reveals the particle shape information from the difference of the two PSDs for the same material by measuring them with different sizing techniques. Thus, this approach can be utilized for not only quartz but also for the fine particulate coals, minerals, and similar material ground finely.

\section{References}

1. Pabst W. \& Gregorová, E., (2007). ICT Prague 2007, Characterization of particles and particle systems.

2. Allen, T. (1990). Particle Size Measurement, 4th ed., New York: Chapmann and Hall.

3. Jillavenkatesa, A., Dapkunas, S. J., \& Lum, L. H., (2001). Particle Size Characterization, Special Publication 960-1, NIST Recommended Practice Guide, p. 27.

4. Horiba Instruments Inc, (2010). A Guidebook to particle size analysis

5. Stanford, R.E., \& Patterson, B.R., (2007). Controlled particle size distributions using Linear Programming, Powder Technology, 176, 114-122.

6. Cirulis, D., (2017). Particle Size Tracking System vs. Traditional Measurement Techniques, E\&MJ, March, p. 58

7. Kelly, E.G. \& Spottiswood, D.J. (1982). Introduction to mineral processing, John Wiley \&Sons Inc., New York, USA, pp. 21-22.

8. Wills, B.A. \& Napier-Munn, T., (2006). Wills' Mineral Processing Technology, An Introduction to the Practical Aspects of Ore Treatment and Mineral Recovery, 7th revised ed. Elsevier Publisher,

9. Ikechuks, G. A., (2011). The effects of particle size on the wettability of Akwuke coal using continuous flow technique, Proceedings of the World Congress on Engineering and Computer Science, San Francisco, USA, vol. 2, pp. 237-247.

10. Kök, M.V., Özbas, E., Hicyilmaz, C., \& Karacan, Ö., (1997). Effect of particle size on the thermal and combustion properties of coal, Thermochim. Acta, 302, 125-130.

11. Mohns, C.A., (1997). The Effects of Particle Size on the Kinetics of Coal Froth Flotation Master's thesis Queen's University, Ontario, Canada. 
12. Boylu, F., Dincer, H., \& Ateşok, G., (2004). Effect of coal particle size distribution, volume fraction and rank on the rheology of coal-water slurries, Fuel Process. Technol., 85, 241-250.

13. Brikci-Nigassa, M., Garbett, E.S., \& Hedley, A.B., (1982). The effect of coal particle size on the performance of a fluidised bed coal combustor, Prepr. Pap. Am. Chem. Soc. Div. Fuel Chem. (U. S.) 27.

14. Schneider, C. L., Neumann, R. \& Souza, A. S. (2007). Determination of the distribution of size of irregularly shaped particles from laser diffractometer measurements, Int. J. Miner. Process. 82, 30-40.

15. Zhang, Z. Yang, J. Ding, L. Zhao, Y., (2012). An improved estimation of coal particle mass using image analysis, Powder Technol. 229, 178-184.

16. Ko, Y.-D. \& Shang, H., (2011). Time delay neural network modeling for particle size in SAG mills, Powder Technol. 205 250-262.

17. Eshel, G. Levy, G.J., Mingelgrin, U., \& Singer, M.J., (2004). Critical evaluation of the use of laser diffraction for particle-size distribution analysis, Soil Sci. Soc. Am. J. 68 (3) 736-743.

18. Ghasemy, A., Rahimi, E., \& Malekzadeh, A., (2019). Introduction of a new method for determining the particlesize distribution of fine-grained soils, Measurement, 132, 79-86.

19. Oja, M., Tuunila, R., 2000. The influence of comminution method to particle shape, Proceedings of the XXI Int. Min. Proc. Cong., Rome, Italy, July 23-27, p. C4-64-70.

20. Johnston, R.G., \& Reuter, J. M. (1993). Mineral uses in paint and their effect on quality, SME Annual Meeting, Reno, Nevada, 15-18 February.

21. Ulusoy, U., Yekeler, M., Biçer, C. \& Gülsoy, Z., (2006). Combination of the Particle Size Distributions of Some Industrial Minerals Measured by Andreasen Pipette and Sieving Techniques, Particle \&6 Particle Systems Characterization, 23 (6) 448-456.

22. Ulusoy,U., Gulsoy, Ö. Y., Aydogan, N. A., \& Yekeler, M., (2008). Combination of laser diffraction and sieve size distribution by determining the mean shape factors, Particulate Science and Technology, 26, (2) 158-168.

23. Leschonski, K., (1979). Sieve analysis, the cinderella of particle size analysis methods, Powder Technology, 24, $115-124$.

24. Allen, T. (2003). Powder Sampling and Particle Size Determination, Elsevier Science Ltd., pp. 208-250.

25. Rhodes, M. J. (2008). Introduction to particle technology, John Wiley \& Sons Ltd., pp. 12-13.

26. Allen, T., (1992). Particle Size Measurement, Chapman \& Hall. 4th Ed.

27. Igathinathane, C., Ulusoy, U., \& Pordesimo, L.O., (2012). Comparison of particle size distribution of celestite mineral by machine vision Volume approach and mechanical sieving, Powder Technology, 215-216C, 137-146.

28. Lambourne, R., (1993). Paint and Surface coatings-theory and practice; (Ed.), Ellis Horwood Ltd., ISBN 0-13030974-5PGk

29. Levoguer, C., (2013). Using laser diffraction to measure particle size and distribution, May/June MPR, pp. 1118, metal-powder.net

30. Ma, Z., H. G. Merkus, J. G. A. E de Smet, C. Heffels, \& Scarlett, B., (2000). New developments in particle characterization by laser diffraction: size and shape, Powder Technology, 111: 66-78.

31. Kippax, P., (2005). Measuring particle size using modern laser diffraction techniques, PaintÉG Coatings Industry, August.

32. Austin, L. G., (1998). Conversion Factors to convert particle size distributions measured by one method to those measured by another method, Part. Part. Syst. Charact. 15: 108-111.

33. Austin, L. G., and I. Shah. 1983. Powder Technol., 35: 271-278.

34. Ulusoy U., \& Yekeler, M., (2004). Variation of critical surface tension for wetting of minerals with roughness determined by Surtronic 3+ instrument, Int. J. of Miner. Process., 74, (1-4): 61-69.

35. Ulusoy, U., Yekeler, M. \& Hiçyılmaz, C., (2003). Determination of the shape, morphological and wettability properties of Quartz and their correlations, Minerals Engineering, 16, (10): 951-964.

36. Stokes, G. G., (1891). Mathematical and Physical Paper III, Cambridge University Press,

37. Sympatec Company, Clausthal-Zellerfeld, Germany. http://www.sympatec.com/LaserDiffraction/LaserDiffraction.html

38. Austin, L. G., Tras, O., Dumm, T. F., \& Koka, V. R., (1998). Part. Part. Syst. Charact. 5, 13-15.

39. Kaya, E. Hogg, R. Kumar, S. R., (2002). Particle shape modification in comminution, KONA, 20, pp. 188-195.

40. Austin, L. G., Yekeler, M., Dumm, T. F., \& Hogg, R., (1990). The kinetics and shape factors of ultrafine dry grinding in a laboratory tumbling ball mill, Part. Syst. Charact., 7, 4, pp. 242-247.

41. Bond, F. C., (1954). Control particle shape and size, Chem. Eng., pp. 1028-1032.

42. Heywood, H., (1961). Powders in Industry, Soc. Chem. Ind., pp. 25-26. 
43. Durney, T. E., \& Meloy, T. P., (1986). Particle shape effects due to crushing method and size, Int. J Miner. Proc., 16, 109-123.

44. Lefond, S. J, (1983). Industrial Minerals and Rocks, $5^{\text {th }}$ ed., vol. 2, SME, Littleton, 